\title{
Tiotropium Bromide Monohydrate
}

National Cancer Institute

\section{Source}

National Cancer Institute. Tiotropium Bromide Monohydrate. NCI Thesaurus. Code C61974.

The monohydrate bromide salt form of tiotropium, a quaternary ammonium derivative of atropine and a long-acting muscarinic receptor antagonist, with bronchodilating activity. Upon inhalation, tiotropium binds to and blocks mainly muscarinic M3 receptors located on smooth muscle cells, thereby preventing smooth muscle contraction. 